\title{
COTIDIANO, MEDIAÇÃO PEDAGÓGICA E FORMAÇÃO DE CONCEITOS: UMA CONTRIBUIÇÃO DE VYGOTSKY AO ENSINO DE GEOGRAFIA
}

\author{
Lana de Souza Cavalcanti
}

\begin{abstract}
RESUMO: Este texto faz uma síntese da teoria vygotskyana sobre o desenvolvimento dos processos psicológicos superiores, destacando alguns conceitos dessa teoria, tais como internalização, mediação semiótica, Zona de Desenvolvimento Proximal, conceitos cotidianos e conceitos científicos, que são especialmente instrumentalizadores da análise dos processos educativos e de sua relação com o desenvolvimento dos processos psicológicos. A partir de uma síntese do pensamento de Vygotsky, o texto busca especificar possíveis contribuições dessa teoria para o ensino de geografia, particularmente para a formação de conceitos geográficos.

Palavras-chave: Psicologia histórico-cultural. Formação de conceitos. Ensino de geografia.
\end{abstract}

\section{EVERYDAY LIFE, PEDAGOGICAL MEDIATION AND CONCEPT FORMATION: HOW VYGOTSKY CONTRIBUTED TO GEOGRAPHY TEACHING}

ABSTRACT: This paper synthesizes the theory on the development of the higher mental processes by Vygotsky. It highlights some of its concepts, as internalization, semiotic mediation, Zone of Proximal Development, daily and scientific concepts, which are quite instrumentally helpful to analyze the educational processes and their relationship to the development of the psychological processes. After this synthesis of Vygotsky's thought, it seeks to specify possible contributions of that theory to geography teaching, particularly to the formation of geographical concepts.

Key words: Historical-cultural psychology. Concept formation. Geography teaching.

Doutora em geografia pela Universidade de São Paulo (USP) e professora do Instituto de Estudos Sócio-Ambientais (IESA) da Universidade Federal de Goiás (UFG). E-mail: 1s.cavalcanti@uol.com.br 
uero iniciar este texto expondo de forma breve o sentimento de impotência que me invadiu diante do desafio de escrever sobre a contribuição de Vygotsky para o ensino de geografia. Nos últimos anos, desde a finalização da minha tese de doutorado (Cavalcanti, 1998), na qual fiz um estudo sistemático de algumas obras desse autor, tenho procurado seguir suas orientações para uma compreensão dos processos didáticos necessários ao ensino de geografia voltado para a construção de conhecimentos pelos alunos. A obra de Vygotsky é muito vasta e densa em si mesma, além disso é de extrema fecundidade no sentido de permitir sua exploração e aprofundamento por inúmeros seguidores (Leontiev, Luria, Davidov e outros) e estudiosos como Ricardo Baquero (1996), Harry Daniels (2002, 2003), James V. Wertsch e outros (1998), Wertsch \& Tulviste (2002) e, entre os brasileiros, Oliveira (1995), Castorina (1995, 1998), Rego (1995), Góes (1991, 2001) Souza (1994), Freitas(1994)), tornando-a atual e referência importante para práticas educativas. A tranquiilidade para aceitar o desafio que me foi colocado somente surgiu ao entender que a minha tarefa não seria a de analisar a obra de Vygotsky, como muitos de seus estudiosos e especialistas têm feito, mas a de destacar dessa obra alguns elementos que podem ajudar a refletir sobre práticas educativas de geografia, valendo-me dos textos de Vygotsky, de alguns especialistas em sua teoria e de meus próprios.

Sendo assim, apresento uma leitura particular de alguns aspectos do pensamento de Vygotsky, com interesse mais direto para a metodologia de ensino de disciplinas específicas, no caso a geografia escolar. Para tanto, inicio com uma síntese da teoria vygotskyana sobre o desenvolvimento dos processos psicológicos superiores; em seguida, destaco alguns conceitos dessa teoria que são especialmente instrumentalizadores da análise dos processos educativos e de sua relação com o desenvolvimento dos processos psicológicos e finalizo com a busca de especificar possíveis contribuiçóes dessa teoria para o ensino de geografia.

Fundamentos da psicologia histórico-cultural do pensamento de Vygotsky

Vygotsky foi um psicólogo russo, com formação em medicina e direito, entre outras, que nasceu em Orsha em 1896 e se radicou em Gomel, ambas cidades da Bielo-Rússia, sendo que Gomel situava-se em território de confinamento de judeus na Rússia czarista. Desenvolveu sua produção psi- 
cológica basicamente em Moscou, onde faleceu em 1934, com 38 anos de idade. Esse contexto ajuda a entender o trabalho de Vygotsky voltado para a demonstração do caráter histórico e social da mente humana e da possibilidade de intervir em seu desenvolvimento. Entre suas principais obras, e de maior repercussão no Brasil, pode-se citar: Formação social da mente (1984), Pensamento e linguagem (1993) e A Construção do pensamento e da linguagem (2001).

Em suas pesquisas, Vygotsky buscava elaborar categorias e princípios para desenvolver uma teoria psicológica que desse conta do psiquismo humano, fundamentando-se na dialética. Uma preocupação inicial, nessa busca, era a de estabelecer interlocução com os psicólogos russos da época demonstrando que a consciência e o comportamento, objetos da investigação psicológica, não poderiam ser entendidos separadamente, mas como uma totalidade unificada. Sendo assim, tinha como motivação em sua obra identificar o mecanismo do desenvolvimento de processos psicológicos no indivíduo (formação da consciência) por meio da aquisição da experiência social e cultural.

Uma das idéias básicas nessa teoria psicológica de Vygotsky é a do caráter histórico e social dos processos psicológicos superiores (únicos dos seres humanos), ou seja, a idéia de que esses processos, que têm a característica de alto grau de universalização e descontextualização da realidade empírica imediata como, por exemplo, é o caso do desenvolvimento da escrita, originam-se na vida social. Para explanar esse raciocínio, Vygotsky (1988, p. 114) assim se expressa:

Todas as funções psicointelectuais superiores aparecem duas vezes no decurso do desenvolvimento da criança: a primeira vez, nas atividades coletivas, nas atividades sociais, ou seja, como funçôes interpsíquicas; a segunda, nas atividades individuais, como propriedades internas do pensamento da criança, ou seja, como funções intrapsíquicas. ${ }^{1}$

A idéia a se ressaltar aqui é a de que as funções mentais superiores do homem (percepção, memória, pensamento) desenvolvem-se na sua relação com o meio sociocultural, relação essa que é mediada por signos. Assim, o pensamento, o desenvolvimento mental, a capacidade de conhecer o mundo e de nele atuar é uma construção social que depende das relações que o homem estabelece com o meio. Nessa construção, nesse processo de desenvolvimento das funções mentais superiores, tem prioridade, então, o plano interpsíquico, o interpessoal, o social. Segundo Baquero 
Cotidiano, mediação pedagógica e formação de conceitos: uma contribuição de Vygotsky...

(1998), essa é uma concepção particular das origens do psiquismo, que contém critérios de compreensão dos processos de desenvolvimento. Esse processo é culturalmente organizado, destacando-se aí o papel específico do ensino escolar, conforme o autor (1998, p. 26) explica:

Essa especificidade deriva do fato de que o desenvolvimento dos Processos Psicológicos Superiores, no contexto da teoria, depende essencialmente das situações sociais específicas em que o sujeito participa. [Os Processos Psicológicos Superiores] pressupõem a existência de processos elementares, mas estes não são condição suficiente para sua aparição (...) $\mathrm{O}$ processo é na verdade muito mais complexo, porque o desenvolvimento parece incluir mudanças na estrutura e função dos processos que se transformam.

O que o autor chama a atenção nesse raciocínio é que o desenvolvimento de funções mentais superiores não decorre de uma evolução intrínseca e linear das funções mais elementares; ao contrário, aquelas são funções constituídas em situações específicas, na vida social, valendo-se de processos de internalização, mediante uso de instrumentos de mediação. Nessa afirmação, destacam-se os conceitos de internalização e de mediação.

A internalização é um processo de reconstrução interna, intrassubjetiva, de uma operação externa com objetos que o homem entra em interação. Trata-se de uma operação fundamental para o processo de desenvolvimento de funçôes psicológicas superiores e consiste nas seguintes transformaçôes: de uma atividade externa para uma atividade interna e de um processo interpessoal para um processo intrapessoal. $\mathrm{Na}$ explicação desse processo de internalização, os estudiosos de Vygotsky têm destacado dois aspectos que me parecem fundamentais para a linha de raciocínio que está sendo desenvolvida neste texto. Primeiro é o percurso dessa internalização das formas culturais pelo indivíduo, que tem início em processos sociais e se transforma em processos internos, interiores do sujeito, ou seja, por meio da fala chegase ao pensamento. O segundo aspecto é o da criação da consciência pela internalização, ou seja, Vygotsky alerta, como dizem seus estudiosos, para o fato de que esse processo não é o de uma transferência (ou cópia) dos conteúdos da realidade objetiva para o interior da consciência, pois esse processo é, ele próprio, criador da consciência. Considero conveniente destacar esses dois aspectos porque eles demonstram a importância de processos socioculturais específicos para o percurso da formação da consciência, como é o caso de processos do ensino escolar, e que essa formação é uma constru- 
ção ativa do sujeito que transforma, via internalização, os conteúdos externos em conteúdos da consciência. ${ }^{2}$

A formação da consciência, das funções psicológicas superiores, ocorre, então, a partir da atividade do sujeito, com a ajuda de instrumentos socioculturais, que são os conteúdos externos, da realidade objetiva. Segundo Baquero (1998, p. 36), os instrumentos de mediação são uma fonte de desenvolvimento e também de reorganização do funcionamento psicológico global:

O desenvolvimento (...) quando se refere à constituição dos Processos Psicológicos Superiores, poderia ser descrito como a apropriação progressiva de novos instrumentos de mediação ou como o domínio de formas mais avançadas de iguais instrumentos (...) (Esse domínio) implica reorganizações psicológicas que indicariam, precisamente, progressos no desenvolvimento psicológico. Progressos que (...) não significam a substituição de funções psicológicas por outras mais avançadas, mas, por uma espécie de integração dialética, as funçōes psicológicas mais avançadas reorganizam o funcionamento psicológico global variando fundamentalmente as interrelações funcionais entre os diversos processos psicológicos.

Pelo que foi exposto até aqui, tem-se que o conhecimento na perspectiva histórico-cultural de Vygotsky é uma produção social que emerge da atividade humana, que é social, planejada, organizada em ações e operações e socializada (Pino, 2001). Essa ação humana está subordinada à criação de meios técnicos e semióticos, estes últimos particularmente destacados por Vygotsky. A atividade humana é produtora, por meio dela o homem transforma a natureza e a constitui em objeto de conhecimento (produção cultural) e, ao mesmo tempo, transforma a si mesmo em sujeito de conhecimento.

A relação sujeito-objeto, nessa perspectiva, não é de interação, é dialética, é contraditória e é mediada semioticamente. A mediação semiótica, por sua vez, é uma mediação social, pois os meios técnicos e semióticos (a palavra, por exemplo) são sociais.

Dessa compreensão pode-se refletir sobre o real e a sua representação. $\mathrm{O}$ mundo, na perspectiva aqui trabalhada, só pode ser conhecido como objeto de representação que dele se faz. E esse mundo só pode ser um mundo para si, para o sujeito que o internaliza, depois que ele foi um mundo para os outros, ou seja, o conhecer é um processo social e histórico, não um fenômeno individual e natural. No processo de conhecer, os 
Cotidiano, mediação pedagógica e formação de conceitos: uma contribuição de Vygotsky...

objetos são apreendidos por sinais - imagens sensoriais - que se encontram colados à singularidade do objeto. Para o processo de descolamento do singular do objeto e sua generalização e abstração, a imagem tem de ser representada pelo signo. Mas, diferentemente dos animais, os sinais que os homens captam do mundo carregam-se de significação social e cultural. Desde a infância, a criança já capta o objeto semiótico, ou seja, a imagem com sua significação (com o uso da palavra).

Sendo assim, a representação é tanto uma função (tornar presente algo que não está presente) quanto o objeto representado (o significante). Para Vygotsky, a palavra é o signo que serve tanto para indicar o objeto como para representá-lo, como conceito, sendo nesse último caso, um instrumento do pensamento.

Pode-se depreender daí que há uma relação estreita entre a atividade produtiva e a atividade cognitiva, uma vez que a atividade produtiva implica conhecimento e que o conhecimento pressupõe uma produção sociocultural, isto é, implica a conversão dos saberes historicamente produzidos pelos homens em saberes do indivíduo. É nessa atividade cognitiva que o homem se apropria dos saberes historicamente produzidos e dos modos de saber e de pensar desses homens. Conforme Pino (2001, p. 41):

Não é na mera manipulação de objetos que a criança vai descobrir a lógica dos conjuntos, das seriaçôes e das classificações; mas é na convivência com os homens que ela descobrirá a razão que os levou a conceber e organizar dessa maneira as coisas. Evidentemente, nesse processo de apropriação cultural o papel mediador da linguagem (a fala e outros sistemas semióticos) é essencial.

O autor destaca no processo de apropriação cultural o papel mediador da linguagem. Com efeito, a linguagem tem um papel importante na teoria de Vygotsky sobre a formação da consciência, compreendida na relação de síntese entre organismo e ambiente. A visão deste autor, e de outros como Bakhtin (1992), sobre a linguagem e sua construção está ligada ao pensamento dialético e, portanto, busca compreendê-la no quadro das relações contraditórias e dialéticas entre um constructo objetivo e racional de significados e uma criação individual e subjetiva de sentidos. Para Vygotsky, a linguagem é desde o início social e ambientalmente orientada e desenvolvida no sujeito por um processo intrapsíquico, destacando-se aí o discurso egocêntrico. Em outras palavras, a fala de uma criança em pro- 
cesso de aquisição da língua é inicialmente social, evocando o meio externo, e gradativamente se torna um sistema de signos. Conforme a explicação de Emerson (2002, p. 153):

Quando isso ocorre, sua fala se diferencia em dois sistemas de pensamento separados mas engrenados: um continua a se ajustar ao mundo externo e emerge como fala social adulta; o outro sistema começa a se "internalizar" e se torna, gradualmente, uma linguagem pessoal, grandemente abreviada e predicativa (...). Nesse discurso interior, o sentido da palavra - "um todo dinâmico, fluido, complexo" - ganha predominância sobre o significado da palavra”.

Aqui é importante destacar a distinção que Vygotsky faz entre sentido e significado da palavra, pelo que isso traz de contribuição para as relações entre eles em situaçôes de ensino: "O sentido de uma palavra é a soma de todos os eventos psicológicos que a palavra desperta em nossa consciência (...). O significado é apenas uma das zonas do sentido, a mais estável e precisa" (1993, p. 125). No discurso interior, o sentido prevalece sobre o significado. A linguagem, então, é uma ferramenta da consciência, que tem a função de composição, de controle e de planejamento do pensamento e, ao mesmo tempo, tem uma função de intercâmbio social. Os significados das palavras compõem a consciência individual, mas são, ao mesmo tempo, construídos no âmbito interindividual, têm um caráter social.

Nesse raciocínio, destacam-se as relações de interdependência entre pensamento e fala, entre fala interior e fala exterior, entre sentido e significado, entre homem e mundo. $\mathrm{Na}$ sua relação cognitiva com o mundo, o homem exerce uma atividade mediada por instrumentos e signos, como já está assinalado neste texto; nessa atividade, como também já foi abordado, Vygotsky destaca o processo de internalização como uma reconstrução interna, intersubjetiva, de uma operação externa com objetos em interação.

Entretanto, ainda é necessário ressaltar, a idéia de que a formação de consciência e o desenvolvimento intelectual se dão de fora para dentro, num processo de internalização, não pode implicar um entendimento de passividade do sujeito do conhecimento. Segundo Castorina (1995), os textos de Vygotsky e de seus discípulos parecem mostrar que na internalização há um processo de transformação, de modificação da compreensão individual, há "uma reorganização individual em oposição a uma transmissão automática dos instrumentos fornecidos pela cultura” (1995, 
Cotidiano, mediação pedagógica e formação de conceitos: uma contribuição de Vygotsky...

p. 30). Esse processo pode ser entendido, pois, como uma atividade mental responsável pelo domínio (que significa uma reconstrução, uma transformação) dos instrumentos de mediação do homem com o mundo.

A internalização consiste, como já foi dito, na transformação de uma atividade externa para uma atividade interna e de um processo interpessoal para um processo intrapessoal. Essas transformaçóes são fundamentais para o processo de desenvolvimento de funções psicológicas superiores e interessam particularmente ao contexto escolar, porque ele lida com formas culturais que precisam ser internalizadas.

Nesse ponto chega-se à inter-relação da construção do conhecimento e a cultura. Inicio a análise dessa relação com uma citação de Van der Veer \& Valsiner (apud Baquero, 1998, p. 31) que considero muito relevante para este texto:

(...) as pessoas não apenas possuem ferramentas mentais, elas também são possuídas por elas. Os meios culturais - a fala em particular - não são externos a nossas mentes, mas crescem dentro delas, criando, desse modo, uma "segunda natureza". O que Luria e Vygotsky pensavam é que o domínio dos meios culturais transformará nossas mentes: uma criança que dominou a ferramenta cultural da linguagem nunca será a mesma criança (...). Assim, pessoas pertencentes a diferentes culturas literalmente pensariam de maneiras diferentes, e a diferença não estaria confinada ao conteúdo do pensamento como também à maneira de pensar.

O papel da cultura na construção teórica de Vygotsky é bastante importante e está no cerne de sua explicação sobre o funcionamento mental humano e a mediação semiótica nesse funcionamento. Para este autor, a cultura tem a ver com a existência concreta dos homens em processo sociais, é produto da vida social e da atividade social. Mas, advertem Wertsch \& Tulviste (2002), mesmo que ele não tenha elaborado amplamente esse conceito, a análise que faz de modos de pensar próprios de determinadas pessoas em contextos culturais determinados expressa uma abordagem evolucionista da cultura, que reflete um tipo de perspectiva etnocêntrica, eurocêntrica, da formaçãao cultural, no sentido de considerar algumas culturas superiores a outras.

Embora esse seja um ponto importante para análise de especialistas nesse pensamento, considero que se deve entendê-lo no próprio contexto histórico e cultural/social no qual Vygotsky produziu suas idéias, não invalidando derivações relevantes que se podem fazer da relação entre conhe- 
cimento e cultura para a prática de ensino, entendida como fazendo parte de esferas particulares de atividades socioculturalmente situadas.

Nesse contexto, importa reter a idéia de possibilidades específicas de desenvolvimento do pensamento pelas práticas escolares com a mediação cultural. Estão em foco, nessa mediação, determinados conteúdos culturais e científicos, que não podem ser considerados, absolutamente, em termos de evolução, de mais avançados ou menos avançados, em relação a qualquer outro tipo de conteúdo. Para Wertsch \& Tulviste (op. cit., p. 78), a própria construção da obra de Vygotsky abre um caminho para sair do dilema do eurocentrismo, ao sugerir que em vez de ver formas particulares de funcionamento mental como características de indivíduos ou grupos de maneira geral, essas formas podem ser vistas como características de ambientes específicos. Nessa linha, é mais adequado ver as diferenças de modo de pensar e de produzir de diversos povos em termos de modos coexistentes, mas qualitativamente distintos, de abordar um problema, do que em termos de níveis gerais mais ou menos avançados de funcionamento mental. Assim encarado o papel da cultura escolar na formação de processos superiores de pensamento, não há incoerência entre a psicologia histórico-cultural e as orientaçôes interculturais para as práticas escolares, como tenho procurado adotar para o ensino de geografia (Cavalcanti, 2002).

Os elementos básicos da teoria de Vygotsky sobre o desenvolvimento do pensamento humano, que foram aqui destacados, ajudam a encaminhar a linha de raciocínio que busca explicitar um entendimento das relações entre essa teoria e uma orientação metodológica para o ensino de geografia. Antes de especificar essa área do ensino, convém abordar ainda alguns aspectos especialmente esclarecedores da especificidade das atividades de ensino formal.

Elementos da mediação semiótica em Vygotsky e o processo de ensinoaprendizagem escolar

Quando Vygotsky propõe uma explicação do desenvolvimento mental, ele enfatiza a não-linearidade entre processos elementares e processos superiores do desenvolvimento, esclarecendo que o desenvolvimento deste último processo ocorre inicialmente em nível interpsíquico, para depois se desenvolver em nível intrapsíquico, e que depende de situações sociais específicas. Para as finalidades deste texto, interessa salientar entre essas situ- 
Cotidiano, mediação pedagógica e formação de conceitos: uma contribuição de Vygotsky...

ações a atividade escolar, a mediação semiótica peculiar que nela acontece e a aprendizagem resultante. ${ }^{3}$ Para Vygotsky, há uma relação de interdependência entre os processos de desenvolvimento do sujeito e os processos de aprendizagem, ${ }^{4}$ sendo a aprendizagem um importante elemento mediador da relação do homem com o mundo, interferindo no desenvolvimento humano. $\mathrm{O}$ ensino escolar, para ele, não pode ser identificado como desenvolvimento, mas sua realização eficaz resulta no desenvolvimento intelectual do aluno, ou seja, o bom ensino é aquele que adianta os processos de desenvolvimento.

Para explicar as possibilidades de a aprendizagem influenciar o processo de desenvolvimento mental, Vygotsky formula o conceito de "Zona de Desenvolvimento Proximal” (ZDP), assim definida: “(...) a distância entre o nível de desenvolvimento real, que se costuma determinar através da solução independente de problemas, e o nível de desenvolvimento potencial, determinado através da solução de problemas sob a orientação de um adulto ou em colaboração com companheiros mais capazes" (1984, p. 97).

Esse conceito, por suas implicações pedagógico-didáticas, tem sido bastante destacado nas análises e propostas sobre ensino escolar que adotam essa linha (cf., por exemplo, Onrubia, 2001; Góes, 1991, 2001; Hedegaard, 2002, Baquero, 2002). De fato, a possibilidade de criar Zonas de Desenvolvimento Proximal no ensino e de, com isso, estimular uma série de processos internos e trabalhar com funçôes e processos ainda não amadurecidos nos alunos, mune o professor de um instrumento significativo na orientação de seu trabalho.

O trabalho escolar com a ZDP tem relação direta com o entendimento do caráter social do desenvolvimento humano e das situações de ensino escolar, levando-se em conta as mediaçóes histórico-culturais possíveis nesse contexto. Para Vygotsky, o aluno é capaz de fazer mais com o auxílio de uma outra pessoa (professores, colegas) do que faria sozinha; sendo assim, o trabalho escolar deve voltar-se especialmente para esta "zona" em que se encontram as capacidades e habilidades potenciais, em amadurecimento. Essas capacidades e habilidades, destaca o autor, uma vez internalizadas, tornam-se parte das conquistas independentes da criança.

O trabalho docente voltado para a "exploração" da ZDP e para a construção de conhecimentos nela possibilitada deve estar atento para a complexidade desse processo de construção pelo aluno, para a complexidade do contexto, que envolve as múltiplas influências sociais presentes nas re- 
lações do aluno na escola, enfim, para a complexidade da própria mediação escolar e das relações com o outro. Góes (2001) chama a atenção para isso, alertando para o fato de que as interações de parceria e cooperação entre crianças e entre elas e o professor podem ser tensas e conflituosas, não podendo ser vistas estritamente no sentido de mediação harmoniosa e de caráter pedagógico homogêneo.

Mesmo quando o conhecimento está sendo efetivamente construído, os processos interpessoais abrangem diferentes possibilidades de ocorrências, não envolvendo apenas, ou predominantemente, movimentos de ajuda. Nos esforços da professora para articular o instrucional e o disciplinar, para manejar os focos de atenção e para conduzir as crianças a elaborações quase categoriais, podemos ver que o papel do outro é contraditório, e que o jogo dialógico, que constitui a relação entre sujeitos, não tende apenas a uma direção; abrange circunscrição, expansão, dispersão e estabilização de significados e envolve o deslocamento "forçado" de certas operações de conhecimento. (Góes, 2001, p. 85)

Essas observações chamam a atenção para a complexidade da mediação pedagógica e confirmam que é fundamental para a construção do conhecimento a interação social, a referência do outro, por meio do qual se podem conhecer os diferentes significados dados aos objetos de conhecimento. Essa mediação, ressaltando-se aí o papel da linguagem, é fundamental para o desenvolvimento do pensamento, dos processos intelectuais superiores, nos quais se encontra a capacidade de formação de conceitos. Conforme Vygotsky (1993, p. 50):

A formação de conceitos é o resultado de uma atividade complexa em que todas as funções intelectuais básicas tomam parte. No entanto, o processo não pode ser reduzido à associação, à atenção, à formação de imagens, à inferência ou às tendências determinantes. Todas são indispensáveis, porém insuficientes sem o uso do signo, ou palavra, como o meio pelo qual conduzimos as nossas operaçôes mentais, controlamos o seu curso e as canalizamos em direção à solução do problema que enfrentamos.

A compreensão do processo de formação de conceitos pelo sujeito é um dos pontos de preocupação de Vygotsky e suas considerações a respeito constituem uma grande contribuição de seu pensamento para o ensino escolar. Segundo este autor, para o conhecimento do mundo, os conceitos são imprescindíveis, pois com eles o sujeito categoriza o real e lhe conforma significados. 
Cotidiano, mediação pedagógica e formação de conceitos: uma contribuição de Vygotsky...

O desenvolvimento do pensamento conceitual, entendendo que ele permite uma mudança na relação cognitiva do homem com o mundo, é função da escola e contribui para a consciência reflexiva do aluno.

Os experimentos realizados por Vygotsky e colaboradores revelaram que a formação de conceitos é um processo criativo e se orienta para a solução de problemas. $\mathrm{O}$ desenvolvimento dos processos que resultam na formação de conceitos inicia-se na infância, mas as funçôes intelectuais básicas para isso só ocorrem na puberdade. É relevante, pois, para a reflexão sobre o ensino, considerar que os conceitos começam a ser formados desde a infância, mas só aos 11, 12 anos a criança é capaz de realizar abstrações que vão além dos significados ligados a suas práticas imediatas. Mas isso não se dá pela idade simplesmente, é preciso levar em conta a experiência. Ou seja, o contexto histórico-cultural do indivíduo vai colocando as situaçôes em que, pela atividade intersubjetiva do sujeito, seja a criança ou o adulto, ocorre a apropriação de significados da linguagem que, por sua vez, forma conceitos desse sujeito. Mais uma vez, é preciso esclarecer que os fundamentos teóricos de Vygotsky não permitem o entendimento de um determinismo/ambientalismo nesse processo. A relação entre o indivíduo e o contexto é interdependente, dialética, contraditória; ou seja, a apropriação de significados depende de contextos determinados, mas, da mesma forma, depende da atividade, da participação de sujeitos determinados.

Vygotsky (1993) distingue três fases no processo de formação de conceitos. A primeira é denominada de "conglomerado vago e sincrético de objetos isolados". A segunda é a do "pensamento por complexos". Nessa fase os objetos isolados se associam na mente da criança devido às suas impressóes subjetivas e "às relações que de fato existem entre esses objetos". Um complexo é um agrupamento concreto de objetos e fenômenos unidos por ligações factuais. Essa fase é importante porque há nela um momento chamado de pseudoconceito, bastante semelhante ao conceito propriamente dito e, inclusive, elo de ligação para a formação dos conceitos. A terceira fase é a de formação de conceitos. Vygotsky a distingue da fase de pensamento por complexos, afirmando que para formar conceitos é necessário

Abstrair, isolar elementos, e examinar os elementos abstratos separadamente da totalidade da experiência concreta de que fazem parte. Na verdadeira formação de conceitos, é igualmente importante unir e separar: a síntese deve combinar-se com a análise. O pensamento por complexos não é capaz de realizar essas duas operações. (Idem, ibid., p. 66) 
Para entender o processo de formação de conceitos, via escolarização, por exemplo, é preciso considerar as especificidades e as relaçôes existentes entre conceitos cotidianos e conceitos científicos, conforme o pensamento de Vygotsky. A esse respeito, ele afirma o seguinte:

Acreditamos que os dois processos - o desenvolvimento dos conceitos espontâneos e dos conceitos não-espontâneos - se relacionam e se influenciam constantemente. Fazem parte de um único processo: o desenvolvimento da formação de conceitos, que é afetado por diferentes condições externas e internas, mas que é essencialmente um processo unitário, e não um conflito entre formas de intelecção antagônicas e mutuamente exclusivas. O aprendizado é uma das principais fontes de conceitos da criança em idade escolar, e é também uma poderosa força que direciona o seu desenvolvimento, determinando o destino de todo o seu desenvolvimento mental. (Idem, ibid., p. 74)

No nível de abstração e de generalização, o processo de formação de conceitos cotidianos é "ascendente", surgindo impregnado de experiência, mas de uma forma ainda não-consciente e "ascendendo" para um conceito conscientemente definido; os conceitos científicos surgem de modo contrário, seu movimento é "descendente", começando com uma definição verbal com aplicações não espontâneas e posteriormente podendo adquirir um nível de concretude impregnando-se na experiência.

As formulações de Vygotsky sobre esse complexo processo de formação de conceitos ajudam os professores a encontrarem caminhos no ensino para cumprir objetivos de desenvolvimento intelectual dos alunos, com a contribuição específica das matérias básicas do currículo escolar, como é o caso da geografia. Com efeito, os conteúdos dessa disciplina têm como um dos eixos de estruturação os desdobramentos de conceitos amplos da ciência a que correspondem, e são encarados como instrumentos para o desenvolvimento dos alunos.

A formação de conceitos geográficos e o processo de ensino-aprendizagem

O texto tem buscado explicitar um entendimento do pensamento de Vygotsky e sua contribuiçãoo para uma orientação metodológica do ensino escolar. Para tanto, destacou-se o papel da aprendizagem no desenvolvimento do sujeito e a importância que tem nesse processo o trabalho com a linguagem, e o estabelecimento de relações dialógicas no ensino. 
Cotidiano, mediação pedagógica e formação de conceitos: uma contribuição de Vygotsky...

$\mathrm{Na}$ relação dialógica, em busca do entendimento, segundo Baktin (apud Emerson, 2002, p. 142-143), há sempre que se considerar a negociação de significados, a negociação de valores, pois cada grupo social cada classe, profissão, geração, religião, região - tem seu modo próprio característico de falar, seu próprio dialeto, suas características. As palavras não podem ser entendidas fora do contexto e dos sujeitos que as falam.

O esforço nesta parte do texto é o de explicitar um pouco mais as contribuições dessa linha de entendimento no que diz respeito ao processo de formação de conceitos, particularmente aqueles conceitos que instrumentalizam um pensamento espacial. Minhas preocupações nessa linha têm sido entender as relações entre o funcionamento mental humano e o contexto cultural, histórico e institucional na formação de um modo de pensar particular; ou seja, compreender os processos de mediação que ocorrem ou que podem ocorrer na escola para que haja intervenção nesse funcionamento do ponto de vista da formação do raciocínio espacial.

Considero sempre pertinentes, no sentido desse esforço investigativo, as perguntas de Vygotsky (1993, p. 71): "O que acontece na mente da criança com os conceitos científicos que lhe são ensinados na escola? Qual a relação entre a assimilação da informação e o desenvolvimento interno de um conceito científico na consciência da criança?”.

Para analisar esse tema e refletir sobre o ensino de geografia, tenho partido de alguns pressupostos: na relação cognitiva de crianças, jovens e adultos com o mundo, o raciocínio espacial é necessário, pois as práticas sociais cotidianas têm uma dimensão espacial, o que confere importância ao ensino de geografia na escola; os alunos que estudam essa disciplina já possuem conhecimentos geográficos oriundos de sua relação direta e cotidiana com o espaço vivido; o desenvolvimento de um raciocínio espacial conceitual pelos alunos depende, embora não exclusivamente, de uma relação intersubjetiva no contexto escolar e de uma mediação semiótica.

Essas e outras orientações metodológicas têm sido atribuídas a uma visão socioconstrutivista do ensino, na qual se considera esse processo como construção de conhecimentos pelo aluno. A afirmação anterior é uma premissa inicial que tem permitido formular uma série de desdobramentos para o ensino de geografia: o aluno é o sujeito ativo de seu processo de formação e de desenvolvimento intelectual, afetivo e social; o professor tem o papel de mediador do processo de formação do aluno; a mediação própria do trabalho do professor é a de favorecer/propiciar a inter-relação (encontro/confron- 
to) entre sujeito (aluno) e o objeto de seu conhecimento (conteúdo escolar); nessa mediação, o saber do aluno é uma dimensão importante do seu processo de conhecimento (processo de ensino-aprendizagem).

Tenho procurado, em outros textos, explicitar o entendimento de socioconstrutivismo que tem orientado meus estudos, consciente de que não há uma concepção única dessa proposta, como está em Cavalcanti (2002, p. 31-32):

A perspectiva socioconstrutivista (...) concebe o ensino como uma intervenção intencional nos processos intelectuais, sociais e afetivos do aluno, buscando sua relação consciente e ativa com os objetos de conhecimento (...). Esse entendimento implica, resumidamente, afirmar que o objetivo maior do ensino é a construção do conhecimento pelo aluno, de modo que todas as açóes devem estar voltadas para sua eficácia do ponto de vista dos resultados no conhecimento e desenvolvimento do aluno. Tais ações devem pôr o aluno, sujeito do processo, em atividade diante do meio externo, o qual deve ser 'inserido' no processo como objeto de conhecimento, ou seja, o aluno deve ter com esse meio (que são os conteúdos escolares) uma relação ativa, uma espécie de desafio que o leve a um desejo de conhecê-lo.

Em propostas construtivistas do ensino importa, então, trabalhar com conteúdos escolares que, tornando-se mediação simbólica dos objetos reais, interfiram na atividade do aluno enquanto sujeito de conhecimento. Essa atividade, por sua vez, é impulsionada pela busca de atribuir significados aos conteúdos que lhe são apresentados.

De acordo com essa concepção, os professores, ao ensinarem geografia, devem ter em mente que essa disciplina se constituiu na história da formação escolar congregando basicamente conhecimentos de uma área científica que pretende ser uma perspectiva de análise da realidade, que é a geográfica. Para tanto, essa área tem constituído um conjunto de conceitos, categorias e teorias, a partir dos quais constrói seu discurso. Pode-se chamar esse discurso de linguagem geográfica. Pois bem, para que o aluno aprenda geografia, não no sentido de assimilar as informações geográficas mas de formar um pensamento que lhe permita analisar a realidade na perspectiva geográfica, é preciso que ele trabalhe com essa linguagem. A aprendizagem geográfica requer, nessa perspectiva, a formação de conceitos geográficos, ainda que não se considere essa formação suficiente. E, sendo assim, o ensino deve se voltar para a apropriação de significados geográ- 
Cotidiano, mediação pedagógica e formação de conceitos: uma contribuição de Vygotsky...

ficos, processo que ocorre na negociação de significados resultante da relação dialógica.

Como propõe Vygotsky, a linguagem é uma ferramenta que se constrói nos processos intersubjetivos para depois se tornar uma ferramenta intra-subjetiva, uma ferramenta do pensamento. É dessa forma que o autor propóe como unidade dos processos da linguagem e do pensamento o significado das palavras. No trabalho com o significado, no diálogo com a linguagem geográfica, na introdução de conceitos científicos e na busca de sua apropriação pelo aluno, está a possibilidade do processo de generalização, que é fundamental para o pensamento conceitual. Conforme Vygotsky (2001, p. 9), a palavra "nunca se refere a um objeto isolado mas a todo um grupo ou classe de objetos. Por essa razão cada palavra é uma generalização latente". A formação de conceitos, segundo ele, resulta de generalizações em níveis diferentes de conceitos, ou seja, consiste em organizá-los em um sistema, tendo como critério o grau de generalização. ${ }^{5}$

Esse entendimento leva a voltar o ensino de geografia para um processo de apropriação cultural específico, para a formação de um modo particular de pensar e de ver a realidade, um modo geográfico, com base no desenvolvimento de conceitos geográficos como ferramentas desse pensamento espacial. É preciso salientar que o desenvolvimento de conceitos é, ao mesmo tempo, uma mudança na forma de lidar praticamente, empiricamente com o objeto e na forma de pensar teoricamente. Nesse sentido, são extremamente úteis as formulações desse autor sobre conceitos científicos e conceitos cotidianos. Essas orientações têm fortes implicações pedagógico-didáticas, como, por exemplo, esta recomendação de Vygotsky (1993, p. 93): "É preciso que o desenvolvimento de um conceito espontâneo tenha alcançado um certo nível para que a criança possa absorver um conceito científico correlato (...) os seus conceitos geográficos e sociológicos devem se desenvolver a partir do esquema simples 'aqui e em outro lugar'”.

Entendo que essa colocação de Vygotsky tem a ver com a relação necessária entre cotidiano, mediação pedagógica e formação de conceitos no desenvolvimento do processo de ensino-aprendizagem. Em relação ao ensino de geografia, tenho insistido na idéia de que encaminhar o ensino sob essa orientação requer um olhar atento para a geografia cotidiana dos alunos. É no encontro/confronto da geografia cotidiana, da dimensão do espaço vivido pelos alunos, com a dimensão da geografia científica, do es- 
paço concebido por essa ciência, que pressupõe a formação de certos conceitos científicos, que se tem a possibilidade de reelaboração e maior compreensão do vivido, pela internalização consciente do concebido. Esse entendimento implica ter como dimensão do conhecimento geográfico o espaço vivido, ou a geografia vivenciada cotidianamente na prática social dos alunos.

É preciso, então, que o professor aguce bastante a sensibilidade para captar os significados que os alunos dão aos conceitos científicos que são trabalhados no ensino. Isso significa a afirmação e a negação, ao mesmo tempo, dos dois níveis de conhecimento (o cotidiano e o científico) na construção do conhecimento, tendo, contudo, como referência imediata, durante todo o processo, o saber cotidiano do aluno. $\mathrm{Na}$ verdade, o raciocínio geográfico só é construído pelos alunos se for encarado como tal, como um processo do aluno, que dele parte e nele se desenvolve. Não se desconsidera, aqui, o importante papel do conhecimento científico e do professor (ele próprio ligado a um contexto histórico-cultural) como mediação do aluno com o objeto a conhecer; ao contrário, o texto insiste no entendimento de que se trata de o aluno aproveitar formas de mediação, de colaboração coletiva, para a construção e o desenvolvimento de funções psicológicas pessoais, de pensamento por conceitos.

O desenvolvimento de um modo de pensar geográfico mais abrangente e abstrato requer, pois, a formação de conceitos.

Alguns conceitos são mais gerais e elementares ao raciocínio geográfico, como os que tenho trabalhado em outros textos, que são: natureza, lugar, paisagem, região, território. Além desses, vários outros são essenciais para compor um modo de pensar que seja instrumento de análise da realidade do ponto de vista espacial, como: ambiente, cidade, campo, identidade cultural, degradação ambiental, segregação espacial, e uma infinidade de outros que compõem a linguagem geográfica. Não é o caso de analisar o conteúdo da geografia escolar em si mesmo, mas de atribuir importância para esse conteúdo como ferramenta intelectual. Nesse caso, não se pode abonar práticas de ensino que se voltam para a memorização, para a associação de palavras, para a definição de fenômenos.

O trabalho com o conteúdo geográfico, para que ele se torne ferramenta do pensamento do aluno, implica a comunicação em sala de aula que busque significados, que considere a experiência imediata do aluno, mas que a extrapole; que busque a generalização dos conceitos e o enten- 
Cotidiano, mediação pedagógica e formação de conceitos: uma contribuição de Vygotsky...

dimento de sistemas conceituais; que busque também trabalhar com outras dimensões da formação humana, como a emocional, a social, e não apenas a cognitiva, a racional, que está mais ligada à formação de conceitos. Segundo Vygotsky, na comunicação sobre as palavras, via escolarização, é que a compreensão social se torna disponível para a compreensão individual e para a formação de conceitos (Daniels, 2003).

Apenas para exemplificar, pode-se partir de um conteúdo geográfico específico e procurar entender as diferenças entre um trabalho voltado para a memorização e definição de palavras e um trabalho voltado, não exclusivamente, para a formação de conceitos. Tenho investido, nesse sentido, no tema cidade como conteúdo geográfico. A observação do material didático e do trabalho docente convencional com esse tema, no ensino fundamental e médio, tem mostrado que se trata de um tema complexo, cuja análise do ponto de vista geográfico envolve um sistema amplo de conceitos, muita informação, e requer desenvolvimento de habilidades psicomotoras de orientação e localização espacial.

Para que o ensino de cidade torne esse conceito uma ferramenta para a análise geográfica do mundo pelo aluno, não é uma boa orientação apresentar para o aluno um conjunto de conceitos com sua definição pronta, como: o que é cidade, o que é processo de urbanização, o que é conurbação, o que é metrópole, o que é rede urbana, e tantas outras definiçôes. Observa-se que muitas vezes, com essa orientação, o aluno "aprende" (ou reproduz verbalmente) todas essas definiçôes que compōem o conteúdo sobre cidade, acompanhadas de inúmeras informaçōes sobre diferentes cidades no mundo e no Brasil, mas não consegue se utilizar dessas informaçōes para analisar fatos, fenômenos que lidam praticamente, não "aprende" sobre a própria cidade em que vive, que na maioria das vezes não compõe o conteúdo curricular da escola. Sobre essa prática no ensino, comenta Vygotsky (2001, p. 247):

A experiência pedagógica nos ensina que o ensino direto de conceitos sempre se mostra impossível e pedagogicamente estéril. O professor que envereda por esse caminho costuma não conseguir senão uma assimilação vazia de palavras, um verbalismo puro e simples que estimula e imita a existência dos respectivos conceitos na criança mas, na prática, esconde o vazio. Em tais casos, a criança não assimila o conceito mas a palavra, capta mais de memória que de pensamento e sente-se impotente diante de qualquer tentativa de emprego consciente do conhecimento assimilado. No fundo, esse método de ensino de conceitos é a falha prin- 
cipal do rejeitado método puramente escolástico de ensino, que substitui a apreensão do conhecimento vivo pela apreensão de esquemas verbais mortos e vazios.

Diferentemente, o ensino voltado para a formação de conceitos aborda o tema da cidade buscando o encontro/confronto da experiência imediata e cotidiana do aluno com sua cidade e o conceito abrangente, se se quiser científico, de cidade, envolvendo um sistema conceitual. Nesse intuito, as definições e as informações são secundarizadas no processo, dando-se prioridade para a comunicação e a atribuição/negociação de significados sobre determinadas palavras ou conjunto de palavras: pode-se começar, por exemplo, com a cidade como arranjo espacial - discute-se aqui o que caracteriza a cidade (a vivida pelo aluno e outras apresentadas pelo professor), do ponto de vista da organização da paisagem (discutindo-se o que pode ser entendido como paisagem urbana); um outro conceito a ser trabalhado é o de modo de vida - a cidade, a do aluno e outras, deve ser entendida como o resultado de uma determinada prática social e ao mesmo tempo como uma condição dessa prática -, pode-se continuar procurando trabalhar com a cidade como modo de produção - daí entende-se que ela é um arranjo espacial histórico e que corresponde a determinadas formas de organização da produção social. Com essa orientação, a escola, por meio do ensino de geografia, pode ser um lugar de encontro e confronto entre as diferentes formas de concepção e prática da cidade, cotidianas e científicas, do espaço vivido no bairro, por exemplo, ao espaço da cidade, e desta para o bairro; observando-se sempre a interdependência entre os dois; os conceitos científicos incrustam-se em referentes cotidianos, atingindo um sentido geral na riqueza contextual do pensamento cotidiano (Daniels, 2001, p. 73-74).

A cidade, enquanto conteúdo escolar, não é concebida apenas como forma física, mas como materialização de modos de vida, como um espaço simbólico, e seu estudo volta-se para desenvolver no aluno a compreensão do modo de vida da sociedade contemporânea e de seu cotidiano em particular. Além disso, contribui para o desenvolvimento de habilidades necessárias para os deslocamentos do aluno, seja nos espaços mais imediatos de seu cotidiano, seja em espaços mais complexos, que podem envolver uma rede de cidades. A geografia é uma ciência que estuda o espaço, na sua manifestação global e nas singulares. Sendo assim, os conteúdos geográficos precisam ser "apresentados" para serem trabalhados pelos alunos nessa dupla inserção: a global e a local. 
Cotidiano, mediação pedagógica e formação de conceitos: uma contribuição de Vygotsky...

Nesse processo de formação de conceitos, o professor, como mediador, deve propiciar a expressão, a comunicação da diversidade de símbolos, significados, valores, atitudes, sentimentos, expectativas, crenças e saberes que estão presentes em determinado grupo de alunos, que vive em contexto específico, esforçando-se para entender como cada grupo em particular elabora essa diversidade e para promover o diálogo entre as diversas formas dessa elaboração, buscando atuar nas ZDP, e o diálogo dessas formas com a forma científica estruturada pela ciência geográfica.

Como se percebe, a formação desses conceitos pelo ensino não é uma tarefa simples. Por isso mesmo, considero que as contribuições de Vygotsky dão pistas valiosas para o cumprimento dessa tarefa de modo mais eficaz, entendendo que, nesse processo, as palavras, a linguagem geográfica, são signos que, em princípio, têm o papel de meio na formação de um conceito e, posteriormente, tornam-se seu símbolo no pensamento do aluno.

Na concepção de Vygotsky, não se ensina conceitos aos alunos, pode-se, no máximo, apresentar definições de conceitos (que são uma expressão particular desses conceitos) para serem reproduzidas pelos alunos. $\mathrm{Na}$ verdade, como se tentou demonstrar nesse texto, são os próprios alunos que formam seus conceitos sobre as coisas, e o professor é um mediador nesse processo ao trabalhar com a linguagem geográfica, ao propiciar a negociação/apropriação de significados.

Recebido em maio de 2005 e aprovado em julho de 2005.

\section{Notas}

1. Esse pequeno texto é de extrema importância para a compreensão do pensamento deste autor, como atestam suas inúmeras transcrições, literais ou não, que são feitas por diferentes autores que tratam desse tema, como Wertsch e Tulviste (2002); Baquero (1998); Daniels (2002).

2. Wertsch \& Tulviste (1998) chamam a atenção para as discussōes em torno desse processo e de como poder-se-ia interpretar que Vygotsky estaria aí dando relevo apenas ao papel ativo do meio ambiente, sugerindo que os processos sociais e culturais determinaria os processos individuais. Esses autores concordam com o pouco desenvolvimento da sua compreensão sobre a linha natural do desenvolvimento individual, no entanto, entendem que sua própria teoria descarta essa visão uma vez que analisa a ação humana como uma tensão inerente entre os instrumentos de mediação e o indivíduo, criativo, que os usam em instância concretas.

3. Para aprofundar a pesquisa sobre esses processos, orientações didáticas mais precisas e com maior fundamento teórico, destacando, nesse sentido, categorias como participação, ação e 
atividade, podem ser encontradas em vários teóricos que seguiram Vygotsky no entendimento do caráter histórico-cultural do desenvolvimento humano, como Davydov, Wertsch (cf. Daniels, 2002).

4. Embora considere necessária a análise da interlocução de Vygotsky com Piaget, particularmente na análise da relação entre desenvolvimento e aprendizagem, e esteja ciente de polêmicas sobre as possíveis aproximações entre esses dois teóricos, a opção foi a de não abordar essas questóes no presente texto, por entender que ao demarcar meu entendimento da abordagem histórico-cultural dos fundamentos e postulados de Vygotsky, encaminho a possibilidade de trabalhar com essa interlocução em outros momentos.

5. Vygotsky (1993, p. 80) explica: "Parece-nos óbvio que um conceito possa submeter-se à consciência e ao controle deliberado somente quando começa a fazer parte de um sistema. Se consciência significa generalização, a generalização, por sua vez, significa a formação de um conceito supra-ordenado que inclui o conceito dado como um caso específico. Um conceito supra-ordenado implica a existência de uma série de conceitos subordinados (...). É nossa tese que os rudimentos de sistematização primeiro entram na mente da criança por meio do seu contato com os conceitos científicos, e são depois transferidos para os conceitos cotidianos, mudando a sua estrutura psicológica de cima para baixo."

\section{Referências bibliográficas}

BAKHTIN, M. Marxismo e filosofia da linguagem. São Paulo: Hucitec, 1992.

BAQUERO, R. Vygotsky e a aprendizagem escolar. Porto Alegre: Artes Médicas, 1998.

CASTORINA, J.A. O debate Piaget-Vygotsky, a busca de um critério para sua avaliação. In: CASTORINA, J.A. et al. Piaget-Vygotsky: novas contribuições para o debate. São Paulo: Ática, 1995.

CASTORINA, J.A. Piaget e Vigotsky: novos argumentos para uma controvérsia. Cadernos de Pesquisa, São Paulo, n. 105, p. 160-183, nov. 1998.

CASTORINA, J.A. et al. Piaget-Vygotsky: novas contribuiçōes para o debate. São Paulo: Ática, 1995.

CAVALCANTI, L.S. Geografia, escola e construçāo de conhecimentos. Campinas: Papirus, 1998.

CAVALCANTI, L.S. Geografia e práticas de ensino. Goiânia: Alternativa, 2002.

COLL, C. et al. O construtivismo na sala de aula. São Paulo: Ática, 2001.

DANIELS, H. (Org.). Uma introdução a Vygotsky. São Paulo: Loyola, 2002. 
Cotidiano, mediação pedagógica e formação de conceitos: uma contribuição de Vygotsky...

DANIELS, H. Vygotsky e a pedagogia. Trad. Milton Camargo Mota. São Paulo: Loyola, 2003.

EMERSON, C. O mundo exterior e o discurso interior, Bakhtin, Vygotisky e a internalização da língua. In: DAniels, H. (Org.). Uma introdução a Vygotsky. São Paulo: Loyola, 2002.

FREITAS, M.T.A. O pensamento de Vygotsky e Baktin no Brasil. Campinas: Papirus, 1994.

GÓES, M.C. A natureza social do desenvolvimento psicológico. Cadernos Cedes, Campinas, n. 24, p. 17-24, 1991.

GÓES, M.C. A construção de conhecimentos e o conceito de zona de desenvolvimento proximal. In: MorTimer, E.F.; SMOlKA, A.L.B. (Org.). Linguagem, cultura e cognição: reflexões para o ensino e a sala de aula. Belo Horizonte: Autêntica, 2001. p. 77-88.

HEDEGAARD, M. A zona de desenvolvimento proximal como base para o ensino. In: Daniels, H. (Org.). Uma introdução a Vygotsky. São Paulo: Loyola, 2002.

MORTIMER, E.F.; SMOLKA, A.L.B. (Org.). Linguagem, cultura e cognição: reflexões para o ensino e a sala de aula. Belo Horizonte: Autêntica, 2001.

OLIVEIRA, M.K. Pensar a educação, contribuições de Vygotsky. In: Castorina, J.A. et al. Piaget-Vygotsky: novas contribuições para o debate. São Paulo: Ática, 1995. p. 51-83.

ONRUBIA, J. Ensinar: criar zonas de desenvolvimento proximal. In: Coll, C. et al. O construtivismo na sala de aula. São Paulo: Ática, 2001. p. $123-151$.

PINO, A. O biológico e o cultural nos processos cognitivos. In: MORTIMER, E.F.; SmolKA, A.L.B. (Org.). Linguagem, cultura e cognição: reflexôes para o ensino e a sala de aula. Belo Horizonte: Autêntica, 2001. p. 21-50.

REGO, T.C. Vygotsky: uma perspectiva histórico-cultural em educação. Petrópolis: Vozes, 1995.

SOUZA, S.J. Infância e linguagem: Bakhtin, Vygotsky e Benjamin. Campinas: Papirus, 1994. 
VYGOTSKY, L.S. Formação social da mente. São Paulo: Martins Fontes, 1984.

VYGOTSKY, L.S. Aprendizagem e desenvolvimento intelectual na idade escolar. In: VyGOTSKY, L.S. et al. Linguagem, desenvolvimento e aprendizagem. São Paulo: Ícone; EDUSP, 1988.

VYGOTSKY, L.S. et al. Linguagem, desenvolvimento e aprendizagem. São Paulo: Ícone; EDUSP, 1988.

VYGOTSKY, L.S. Pensamento e linguagem. São Paulo: Martins Fontes, 1993.

VYGOTSKY, L.S. A construção do pensamento e da linguagem. São Paulo: Martins Fontes, 2001.

WERTSCH, J.V. et al. Estudos socioculturais da mente. Porto Alegre: Artes Médicas, 1998.

WERTSCH, J.V.; TULVISTE, P.L.S. Vygotsky e a psicologia evolutiva contemporânea. In: DANiels, H. (Org.). Uma introdução a Vygotsky. São Paulo: Loyola, 2002. 